\title{
Comparative analysis of abdominal fluid cytokine levels in ovarian hyperstimulation syndrome (OHSS)
}

\author{
Balint Farkas ${ }^{1,2^{*}}$ (D), Ferenc Boldizsar ${ }^{3}$, Noemi Bohonyi ${ }^{1}$, Nelli Farkas ${ }^{4}$, Saska Marczi ${ }^{5,6}$, Gabor L. Kovacs ${ }^{7,8,2}$,
} Jozsef Bodis ${ }^{1,2}$ and Miklos Koppan ${ }^{1}$

\begin{abstract}
Background: Ovarian hyperstimulation syndrome (OHSS) is a rare, yet severe, iatrogenic complication of ovulation induction therapy during assisted reproductive procedures. Our group previously detected atypical cells in the ascitic fluid of OHSS patients, although no malignancy developed during follow up. Here, the aim was to perform a comparative analysis of the cytokines present in the abdominal fluid of patients affected by OHSS versus patients with advanced ovarian cancer, a benign adnexal mass, or ovarian endometriosis.

Methods: This prospective, non-randomized study was conducted at the Clinical Center of the University of Pecs Department of Obstetrics and Gynecology/Reproductive Center between October 2016 and March 2018. Abdominal fluid samples were obtained from 76 patients and subjected to Luminex analysis. The samples were collected from patients with OHSS (OHSS; $n=16)$, advanced ovarian cancer (OC; $n=22)$, a benign adnexal mass (BAM; $n=21$ ), or ovarian endometriosis (EM; $n=17$ ). Data were subjected to the non-parametric Kruskal-Wallis test and Spearman's rank correlation coefficient to identify statistical differences between the four study groups.

Results: Leukocytosis and hemoconcentration were detected in the peripheral blood of OHSS patients. Abdominal fluid analysis further revealed significantly higher levels of interleukin (IL)-6, IL-8, IL-10, and transforming growth factor (TGF)- $\beta$ in both the OHSS and OC groups compared to the BAM and EM groups. The highest concentration of vascular endothelial growth factor (VEGF) was detected in the OC group, while a significantly lower level was detected in the OHSS group. Moreover, VEGF levels in OC and OHSS groups were significantly elevated compared to the levels in the BAM and EM groups.
\end{abstract}

Conclusions: Vasoactive and hematogenic cytokines were present at higher levels in both the OHSS and OC abdominal fluid samples compared to the fluid samples obtained from the peritoneal cavity of the BAM patients. It is possible that these cytokines play an important role in the formation of ascites.

Keywords: Ovarian hyperstimulation syndrome, Ovulation induction therapy, Ovarian cancer, Ovarian endometriosis, Benign pelvic mass

\footnotetext{
* Correspondence: dr.balint.farkas@gmail.com

'Department of Obstetrics and Gynecology, University of Pecs, School of Medicine, 17 Edesanyak Str., Pecs, Hungary

${ }^{2}$ Member of the HAS-UP Human Reproduction Scientific Research Group,

Hungarian Academy of Sciences (HAS), Pecs, Hungary

Full list of author information is available at the end of the article
}

C C The Author(s). 2020 Open Access This article is licensed under a Creative Commons Attribution 4.0 International License, which permits use, sharing, adaptation, distribution and reproduction in any medium or format, as long as you give appropriate credit to the original author(s) and the source, provide a link to the Creative Commons licence, and indicate if changes were made. The images or other third party material in this article are included in the article's Creative Commons licence, unless indicated otherwise in a credit line to the material. If material is not included in the article's Creative Commons licence and your intended use is not permitted by statutory regulation or exceeds the permitted use, you will need to obtain permission directly from the copyright holder. To view a copy of this licence, visit http://creativecommons.org/licenses/by/4.0/ The Creative Commons Public Domain Dedication waiver (http://creativecommons.org/publicdomain/zero/1.0/) applies to the data made available in this article, unless otherwise stated in a credit line to the data. 


\section{Background}

Infertility is defined as an individual's inability to reproduce through a natural process. Currently, infertility represents a major healthcare issue in the twenty-first century and it can be the result of male, female, or combined infertility issues. Worldwide, an estimated 48 million women and approximately $7 \%$ of men suffer from infertility [1, 2]. Thus, a growing need for assisted reproduction techniques, particularly in vitro fertilization (IVF) procedures, exists to facilitate conception. However, ovarian hyperstimulation syndrome (OHSS) is a rare, yet potentially life threatening, iatrogenic complication of ovarian induction therapy (OIT) during IVF procedures. OHSS is associated with abdominal pain and/or bloating, nausea, vomiting, and in severe cases, shortness of breath and chest pain. A diagnosis of OHSS is confirmed with laboratory findings of hemoconcentration and ultrasound imaging [3]. Manifestations of the disease can vary from mild to moderate to severe. OHSS often develops after the administration of gonadotropins which are needed to facilitate oocyte maturation and release during IVF procedures. The pathophysiology of OHSS is characterized by the appearance of multiple large luteinized cysts in the ovaries. These cysts are accompanied by a simultaneous increase in vascular permeability which leads to a shift in fluids from the intravascular system to the abdominal and pleural cavity [4].

Despite greater insights into the etiology of OHSS, the exact pathomechanism remains unclear. It has been hypothesized that local vasoactive mediators, such as vascular endothelial growth factor (VEGF), substances belonging to the renin-angiotensin system, and cytokines such as interleukin (IL)-6 and IL-8, play major roles in disease pathogenesis [5-9]. These factors can potentially induce fluid redistribution and massive extravasation, thereby resulting in a state of hypovolemic hyponatremia with hemoconcentration, as well as hypercoagulability $[8,9]$.

A growing concern among public opinion is a potential link between IVF procedures and malignant disease, and this issue may challenge the safety of assisted reproduction. To date, there is no clear evidence which demonstrates a causative role for IVF procedures in breast cancer $[10,11]$ or ovarian cancer [12]. However, we previously detected atypical cells in the ascitic fluid of women with severe OHSS [13]; although, no correlation between the presence of these cells and subsequent malignancy was observed [13]. Therefore, the aim of the current study was to analyze and compare the levels of potentially key mediators of OHSS in the ascitic fluid of women with OHSS, advanced ovarian cancer (OC), or ovarian endometriosis, and in the abdominal fluid of women with benign adnexal masses (BAMs). We hypothesize that these results will provide a better understanding of the pathomechanism of OHSS.

\section{Results}

\section{Demographic characteristics}

The mean age of our study groups were: $34 \pm 5$ years (range: $26-44$ ) for the OHSS group; $64 \pm 13$ years (range: $30-84$ ) for the OC group; $51 \pm 15$ years (range: $24-78$ ) for the BAM group; and $34 \pm 8$ years (range: 18-47) for the ovarian endometriosis (EM) group.

\section{Peripheral blood serum analysis}

The mean serum levels of $\mathrm{Na}^{+}$and $\mathrm{K}^{+}$, as well as activity levels for - aspartate transaminase (ASAT), alanine aminotransferase - (ALAT), and lactate dehydrogenase $(\mathrm{LDH})$, are presented in Fig. 1. In addition, white and red blood cell counts (WBC and RBC, respectively), thrombocyte (TCT) count, blood hemoglobin concentration $(\mathrm{Hgb})$, and hematocrit level $(\mathrm{Htc})$ are also presented in Fig. 1. Application of the non-parametric KruskalWallis test to these data revealed significant differences between the distribution of several values among the study groups (Fig. 1).

\section{Abdominal fluid cytokine level analysis}

From the OHSS patients, an average of 1.11 of ascites were withdrawn. In a Luminex assay, levels of six cytokines were investigated: IL-6, IL-8, IL-10, tumor necrosis factor (TNF)- $\alpha$, VEGF, and transforming growth factor (TGF)- $\beta$. The mean concentration values for IL-6, IL-8, and TGF- $\beta$ were significantly higher in both the OHSS and $\mathrm{OC}$ groups compared to the BAM and EM groups (Fig. 2). The level of VEGF was only significantly higher in the OC group. No statistically significant differences in TNF- $\alpha$ concentrations were observed among the four study groups (Fig. 2). With Spearman's correlation analysis various significant positive correlations were observed in the OHSS group between the WBC count and IL-6 level $(r=0.640 ; p<0.01)$, between the IL-6 and IL10 levels $(r=0.677 ; p<0.01)$, between the IL-6 and VEGF levels $(r=0.652 ; p<0.01)$, and between the IL-10 and VEGF levels $(r=0.615 ; p<0.01)$. In contrast, a significant negative correlation was observed between the serum CA-125 level and VEGF concentration in ascites $(r=-0.584 ; p<0.01)$. Meanwhile, a significant positive correlation was observed between serum CA-125 level and abdominal fluid VEGF concentration in the EM group ( $r=0.564 ; p=0.02)$. In the OC group, a significant positive correlation between peripheral blood TCT level and serum CA-125 level $(r=0.568 ; p<0.01)$, and between TCT and VEGF concentration $(r=0.624 ; p<$ 0.01 ), were observed. In the BAM group, the level of IL6 in abdominal fluid exhibited a significant positive correlation with the levels of IL-8, IL-10, VEGF, and TGF- $\beta$. Similarly, IL-8 levels exhibited a significant positive correlation with the levels of IL-10, VEGF, and 

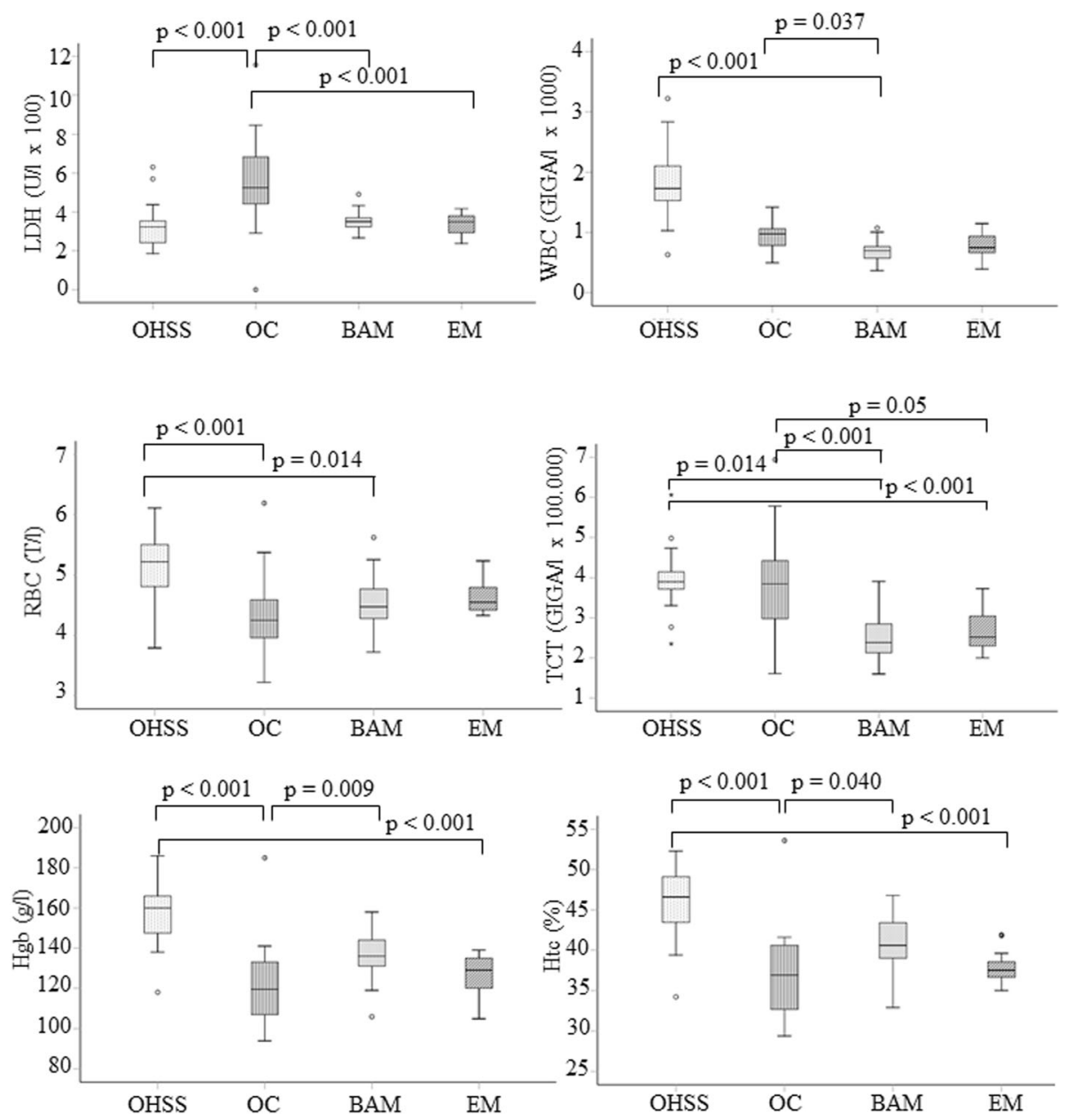

Fig. 1 Levels of LDH and Hgb in peripheral blood serum and hematogram values for the four study groups. Comparison were made with nonparametric Kruskal-Wallis test with Bonferroni post hoc test

TGF- $\beta$, and also between the IL-10 level and the VEGF and TGF- $\beta$ levels (See Fig. 3.)).

\section{Discussion}

Cytokines are a group of polypeptides which are unable to penetrate the lipid bilayer of cells. Despite this limitation, it is still hypothesized that these peptides play an important role in cell signaling. In OHSS, roles for several cytokines have been well-established, thereby suggesting that interactions take place between the immune system and the ovaries during the development of this disease [14]. In the current pilot study, significant alterations in the levels of examined cytokines were observed in the abdominal fluid samples collected from our four study groups.

The pro-inflammatory cytokine, IL-6, is produced by various cells, including monocytes, $\mathrm{T}$ lymphocytes, endothelial cells, and fibroblasts [15]. It has also been proposed that IL- 6 is a major mediator of ascites formation based on its involvement in angiogenesis and hyperpermeability [16]. The present results confirm that high levels of IL-6 are present in the peritoneal cavity of patients with severe OHSS and in patients with advanced ovarian cancer. In contrast, ascites was not detected in the BAM and EM patients. Recent studies also propose that increased serum levels and peritoneal cavity levels of both IL- 6 and IL-10 are associated with factors of worse prognosis in ovarian cancer patients [6,7].

Numerous studies have demonstrated that the vasoactive protein, VEGF, has a key role in OHSS. VEGF belongs to a family of heparin-binding proteins and is able to induce angiogenesis and vascular permeability $[17,18]$. VEGF is secreted by ovarian granulosa cells and its production is stimulated by human chorionic gonadotropin hormone [4, 19-21]. Elevated levels of VEGF have been measured in both serum and ascitic fluid in patients with OHSS $[21,22]$. These results, and those of the current study, are consistent with previous reports that high levels of VEGF are present in the ascitic fluid 

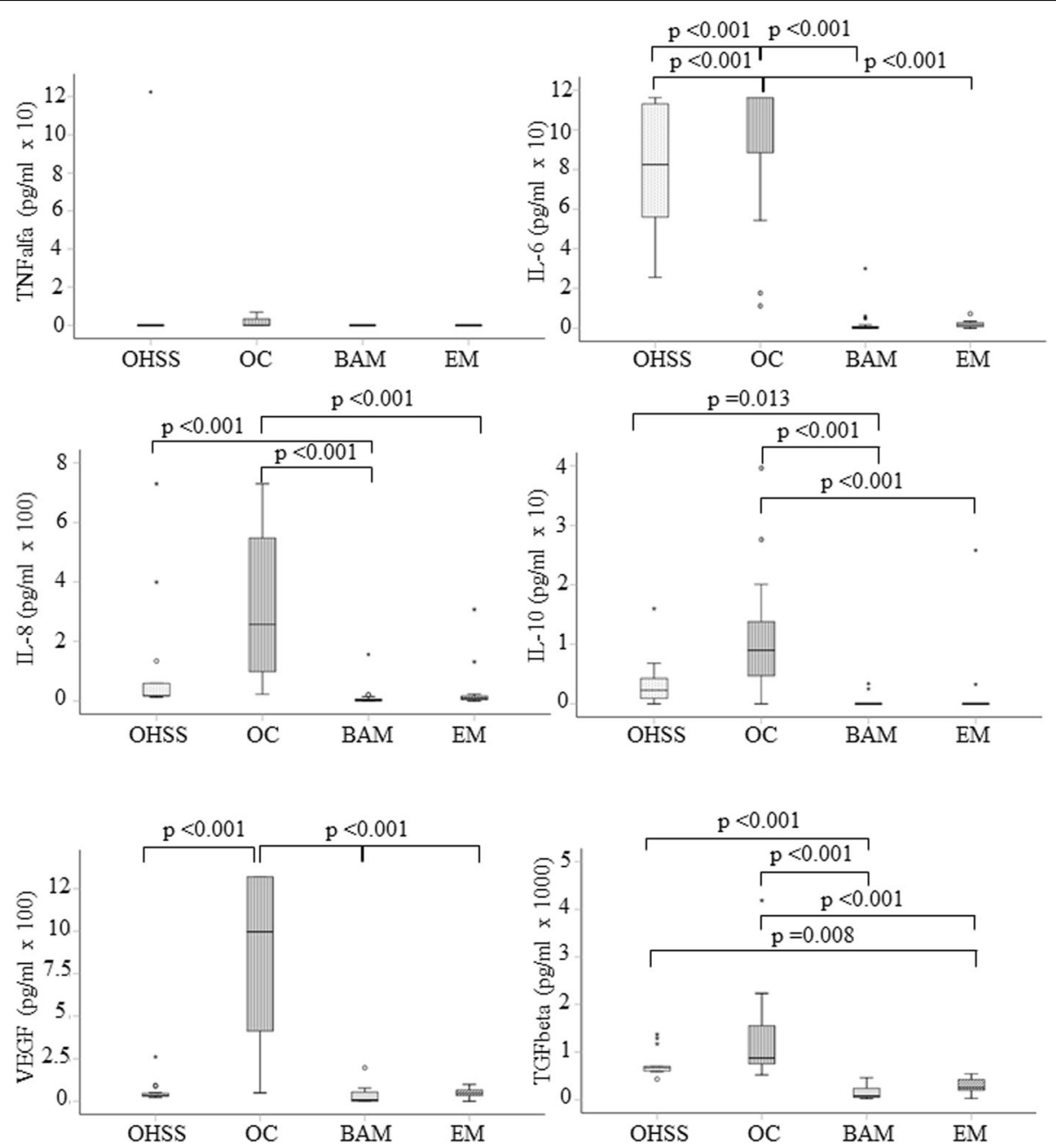

Fig. 2 Cytokine levels in abdominal fluid samples obtained from the peritoneal cavity in the four study groups. Statistical analysis included nonparametric Kruskal-Wallis test with Bonferroni post hoc test

of patients with ovarian cancer [23] and also in the abdominal fluid of OHSS patients [24]. Meanwhile, low levels of VEGF were detected in BAM and EM patients in the present study. We hypothesize that increased production of VEGF is a major factor in the formation of ascites.

Macrophages produce IL-8, an important cytokine in the immune system. This cytokine induces chemotaxistriggered neutrophil migration toward inflammation sites and then stimulates phagocytosis once the neutrophils arrive onsite [25]. Previously, levels of IL-8 and levels of the anti-inflammatory protein, IL-10, were found at higher concentrations in the ascitic fluid of OHSS patients [26, 27]. In our current investigation, significantly higher levels of both IL-8 and IL-10 were detected in the ascites of OHSS and OC patients compared to the levels detected in the abdominal lavage fluid of BAM and EM patients. Moreover, the levels were highest in the ascites of the $\mathrm{OC}$ patients. This finding is consistent with other recently published data [7] and with an angiogenetic role for IL-8 in malignancy [28] and a pivotal immunosuppressive role for IL-10 in OCassociated ascites when activation of dendritic cells via toll-like receptors is compromised [29].

To date, available literature does not indicate a consensus regarding the role of TNF- $\alpha$ in OHSS. For example, while no statistically significant difference was previously found in the amount of TNF- $\alpha$ in the ascites of OHSS patients compared to controls [30], others reported elevated levels in the same experimental setting [31]. The TNF- $\alpha$ data obtained in the present study support a less important role for TNF- $\alpha$ in OHSS.

TGF- $\beta$ is a multifunctional cytokine. In its activated form, it binds TGF- $\beta$ receptors by forming a serine/ threonine kinase complex [31]. Subsequent activation of a signaling cascade leads to downstream activation of various substrates and regulatory proteins. In addition, the transcription of various target genes is induced, 


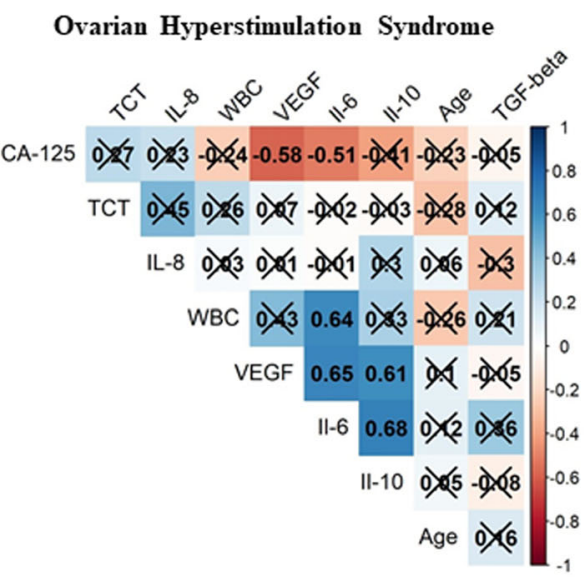

Benign adnexal mass

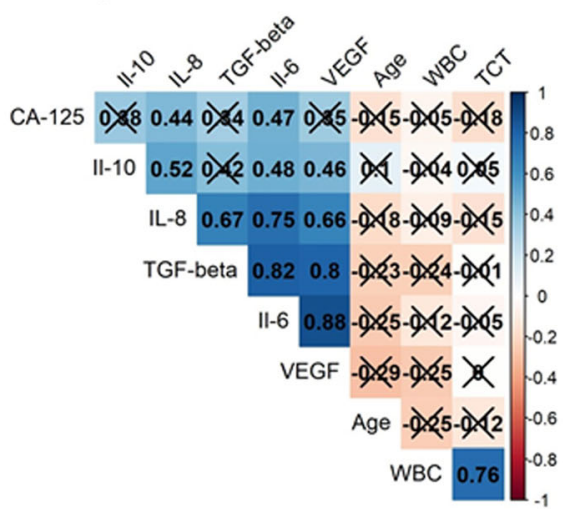

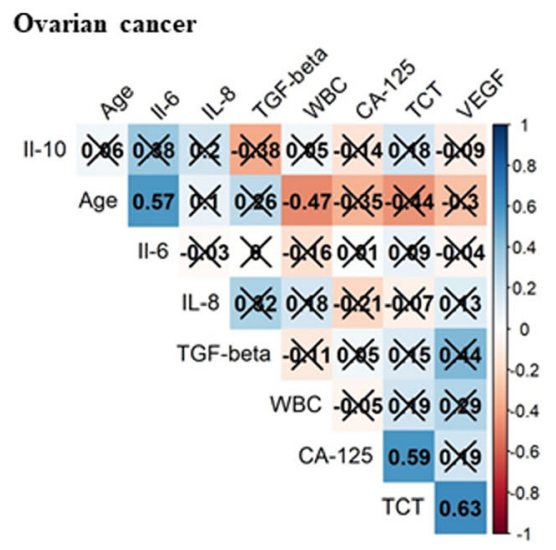

\section{Endometrioma}

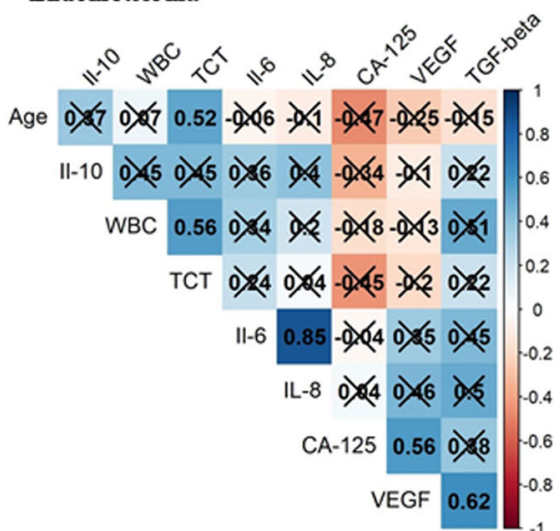

Fig. 3 Spearman correlation matrix of the cytokine values, CA-125 tumor marker parameter and age. Correlation coefficients are shown, red in case of negative, blue in case of positive correlation. X marks: non significant connection

thereby contributing to differentiation, chemotaxis, proliferation, and activation of many immune cells [31]. In our study groups, a significant increase in the levels of TGF- $\beta$ were detected in the OHSS and OC groups relative to the BAM and EM groups. The OC group had the highest concentration of TGF- $\beta$. Among the immunosuppressive cytokines associated with advanced ovarian cancer, it has been proposed that TGF- $\beta$ contributes to impaired anti-tumor immune function [32]. However, the role of TGF- $\beta$ in OHSS remains unknown.

The novelty of our data is that we managed to reveal similarly increased, with no statistically significant difference, in the peritoneal cavity levels of IL-6, IL-8, IL-10, VEGF and TGF- $\beta$ both in OC and OHSS patients, but found statistically significantly lower levels of the same cytokines compared to BAM and EM groups. Despite the mean age alteration between OC and OHSS groups the inflammatory responses might be hard to compare, but the cytokine production trend seem to be similar in these two groups. This might suggest same kind of pathomechanism of the ascites formation both in OHSS and in ovarian malignancy.
There are limitations associated with the present study. These include a relatively low number of participants, a lack of serum cytokine concentration measurements, discrepancies of age between the compared groups, which can influence the inflammatory profile, and some other, potentially important cytokine concentrations were not investigated as yet. Regarding the latter point, IL-2 would have been another cytokine of interest to investigate considering that it has been found at high levels in the peritoneal cavity of OHSS patients [33]. Furthermore, we could not isolate and identify the origin of the atypical cells present in the ascitic fluid of OHSS patients which we previously described $[13,34]$. However, a strength of the present study is the broad spectrum of samples which were examined, including abdominal fluid from patients with various benign adnexal masses and from patients with ovarian "chocolate cysts" (e.g., endometrioma), which served as valid negative controls.

In the future a proposed potential clinical implication of our study would have been to find anti-inflammatory citokine agents to reduce the symptoms of OHSS, and to decrease the severity of the disease. 


\section{Conclusions}

Local pro- and anti-inflammatory cytokines, as well as vasoactive components, play important roles in both the formation of free abdominal fluid and in the pathogenesis of advanced ovarian cancer and OHSS compared with benign ovarian disease and ovarian manifestation of endometriosis. In further studies serum cytokine levels and peritoneal cavity immune cell distribution might worth to investigate, with the aim to reveal which cell population are colonize and produce the described cytokines.

\section{Methods}

\section{Patients and study design}

This prospective, non-randomized study was approved by the University of Pecs Institutional Ethical Review Board (\#5273-2/2012) and was conducted at the Clinical Center of the University of Pecs Department of Obstetrics and Gynecology/Reproductive Center between October 2016 and March 2018. Patient participation was on a voluntary basis and all enrolled participants were older than 18 years of age. Written informed consent was completed if patients had an adnexal mass or if they were diagnosed with OHSS after OIT.

\section{Evaluation of abdominal fluid}

Abdominal fluid samples were obtained during ultrasoundguided culdocentesis of patients with a severe form OHSS $(n=16)$, who represented the investigated population; intraoperative ascites sampling was performed during laparotomy of patients with advanced ovarian cancer (OC) $(n=$ $22)$, who were the malignant disease group; sterile saline was collected after intraoperative pelvic lavage during laparoscopic cystectomy of patients with a benign adnexal mass (BAM; $n=21$ ), who acted as negative controls; and intraoperative sampling of free abdominal fluid was performed during operative laparoscopy for patients with ovarian endometriosis (EM; $n=17)$, used as transient / benign disease group. Clinical and histological diagnoses of the participants are summarized in Table 1.

\section{Peripheral blood analysis}

Peripheral blood samples were collected preoperatively from all the study participants, including 60 patients who were admitted for surgery on the day of intervention, and samples were also collected on the day of hospitalization for the OHSS patients $(n=16)$. Serum levels of $\mathrm{Na}^{+}, \mathrm{K}^{+}, \mathrm{LDH}, \mathrm{ASAT}, \mathrm{ALAT}$, and CA-125 tumor marker were determined. A hemogram was also performed.

\section{Measurement of cytokine levels in abdominal fluid}

Cytokine levels were measured by using the R\&D Systems Human Premixed Multi-Analyte Kit Luminex Assay (Cat. no. LXSAH-6; R\&D Systems, Minneapolis, MN, USA) and a Luminex 200 instrument (R\&D Systems). Levels of IL-6, IL-8, IL-10, TNF- $\alpha$, and VEGF were measured according to the manufacturer's instructions. TGF- $\beta$ levels were measured with the R\&D Systems Magnetic Luminex Performance Assay and MAGPIX MILLIPLEX MAP instrument (MilliporeSigma, Danvers, MA, USA) according to the manufacturer's instructions. Samples above the standard curve were considered to be maximum value,

Table 1 Clinical and histological diagnoses of the participants in the four study groups

\begin{tabular}{|c|c|c|c|c|}
\hline Study group & Histologic Diagnosis & & & Number (n) \\
\hline OHSS & NA & & & 16 \\
\hline \multirow[t]{6}{*}{ Ovarian Cancer } & & FIGO Stage & Grade & 22 \\
\hline & Serous papillary adenocarcinoma & $3 b-c$ & High & 16 \\
\hline & Clear cell adenocarcinoma & NA & NA & 2 \\
\hline & Adenosarcoma & NA & Low & 2 \\
\hline & Adult granulosa cell ovarian tumor & $3 b$ & NA & 1 \\
\hline & Borderline (atypical proliferation) & NA & NA & 1 \\
\hline \multirow[t]{7}{*}{ Benign adnexal mass } & & & & 21 \\
\hline & Ovarian fibroma & & & 6 \\
\hline & Follicular cyst & & & 3 \\
\hline & Granulosa lutein cyst & & & 6 \\
\hline & Adult type teratoma & & & 1 \\
\hline & Borderline tumor (no atypical proliferation) & & & 3 \\
\hline & Paraovarian cyst & & & 2 \\
\hline Endometriosis & Endometrioma of the ovaries & & & 17 \\
\hline
\end{tabular}

FIGO International Federation of Obstetrics and Gynecology 
and samples under the curve sensitivity were annotated as 0 . All data are displayed in $\mathrm{pg} / \mathrm{ml}$.

\section{Statistical analysis}

Statistical analyses were performed by using IBM SPSS Statistic 25 software (IBM Corporation) at the University of Pecs, Institute of Bioanalysis (performed by NF). The total sample size (n) was 76. Comparisons were made between serum and cytokine levels detected for the four study groups according to the non-parametric KruskalWallis test with Bonferroni post hoc test. To examine the relationship between cytokine levels and serum parameters, Spearman's rank correlation coefficient was applied. Mean data are reported \pm standard deviation (SD). Statistical significance was set at $* p<0.05$, or $* * p<0.01$.

\section{Abbreviations}

ALAT: Alanine Aminotransferase; ASAT: Aspartate transaminase; BAM: Benign adnexal mass; EM: Endometriosis; Hgb: Hemoglobin; Htc: Hematocrit, packed cell volume; IL: Interleukin; IVF: In vitro fertilization; LDH: Lactate dehydrogenase; OC: Ovarian cancer; OHSS: Ovarian hyperstimulation syndrome; OIT: Ovulation induction therapy; RBC: Red blood cell; SD: Standard deviation; TCT: Thrombocyte; TGF- $\beta$ : Transforming growth factor-beta; TNF-a: Tumor necrosis factor-alpha; VEGF: Vascular endothelial growth factor; WBC: White blood cell

\section{Acknowledgements}

We would like to express our gratitude to the medical staff of the University of Pecs, Department of Obstetrics and Gynecology, and the Reproduction Center. We especially thank Gabriella Boskovits, head of the OR nurses, for allowing us to collect samples and obtain data. We thank Agnes Kemeny $\mathrm{PhD}$ (Associate Professor at the Department of Pharmacology and Pharmacotherapy, University of Pecs, Medical School) for her help in the TGFbeta MagPix measurement. We would also like to thank Prof. Dr. Peter M. Gocze for his useful comments regarding our manuscript.

\section{Authors' contributions}

BF collected samples, set up the study design, and wrote the manuscript; NB collected samples; FB and SM performed the Luminex assay; NF performed the statistical analyses; MK, GLK, and JB provided financial support and edited the manuscript. All of the authors have read and approved the final manuscript.

\section{Funding}

The current study was funded by grant, GINOP-2.3.2-15-2016-00021, "The use of chip-technology in increasing the effectiveness of human in vitro fertilization". Open access funding provided by University of Pécs (PTE).

\section{Availability of data and materials}

The datasets generated and/or analyzed in the current study are not publicly available in order to prevent compromise of individuals' privacy. However, the data are available from the corresponding author upon reasonable request.

\section{Ethics approval and consent to participate}

This prospective cohort study was approved by the University of Pecs Institutional Ethical Review Board (\#5273-2/2012). All of the participating patients provided written informed consent.

\section{Consent for publication}

The current manuscript does not contain any individual person's data in any form.

\section{Competing interests}

The corresponding author (BF) and two other authors (JB and GLK) have multiple affiliations and JB has received financial support from the Hungarian Academy of Sciences (HAS; Budapest, Hungary). The remaining authors have no conflicts of interest to report regarding the present study.

\section{Author details}

'Department of Obstetrics and Gynecology, University of Pecs, School of Medicine, 17 Edesanyak Str., Pecs, Hungary. ${ }^{2}$ Member of the HAS-UP Human Reproduction Scientific Research Group, Hungarian Academy of Sciences (HAS), Pecs, Hungary. ${ }^{3}$ Department of Immunology and Biotechnology, University of Pecs, School of Medicine, Pecs, Hungary. ${ }^{4}$ School of Medicine, Institute of Bioanalysis, University of Pecs, Pecs, Hungary. ${ }^{5}$ Laboratory of Molecular and HLA Diagnostics, University Hospital Osijek, Clinical Institute of Transfusion Medicine, Osijek, Croatia. ${ }^{6}$ Department of Medical, Chemistry, Biochemistry and Clinical Chemistry, University of Osijek, Faculty of Medicine, Osijek, Croatia. ${ }^{7}$ Szentágothai Research Center, University of Pecs, Pecs, Hungary. ${ }^{8}$ Department of Laboratory Medicine, Faculty of Medicine, University of Pecs, Pecs, Hungary.

Received: 11 November 2019 Accepted: 17 February 2020 Published online: 05 March 2020

\section{References}

1. Mascarenhas MN, Flaxman SR, Boerma T, Vanderpoel S, Stevens GA. National, regional, and global trends in infertility prevalence since 1990: a systematic analysis of 277 health surveys. PLoS Med. 2012;9:e1001356.

2. Lotti F, Maggi M. "ultrasound of the male genital tract in relation to male reproductive health" (PDF). Hum Reprod Update. 2014;21:56-83.

3. Royal College of Obstetricians and Gynaecologists. The management of ovarian hyperstimulation syndrome. Green-top Guideline. 2006:5 Available at: http://www.rcog.org.uk/resources/Public/pdf/green_top_5_ management_ohss_a.pdf. Accessed January 202009.

4. Gomez R, Soares SR, Busso C, Garcia-Velasco JA, Simon C, Pellicer A. Physiology and pathology of ovarian hyperstimulation syndrome. Semin Reprod Med. 2010;28:448-57.

5. Várnagy A, Bódis J, Mánfai Z, Wilhelm F, Busznyák C, Koppán M. Low-dose aspirin therapy to prevent ovarian hyperstimulation syndrome. Fertil Steril. 2010;93:2281-4.

6. Sanguinete MMM, Oliveira PH, Martins-Filho A, Micheli DC, Tavares-Murta BM, Murta EFC, Nomelini RS. Serum IL-6 and IL-8 correlate with prognostic factors in ovarian Cancer. Immunol Investig. 2017;46:677-88.

7. Rodrigues ISS, Martins-Filho A, Micheli DC, Lima CA, Tavares-Murta BM, Murta EFC, Nomelini RS. IL-6 and IL-8 as prognostic factors in peritoneal fluid of ovarian Cancer. Immunol Investig. 2019;22:1-12.

8. Nastri CO, Ferriani RA, Rocha IA, Martins WP. Ovarian hyperstimulation syndrome: pathophysiology and prevention. J Assist Reprod Genet. 2010;27: 121-8.

9. Nelson SM. Prevention and management of ovarian hyperstimulation syndrome. Thromb Res. 2017;151(Suppl 1):S61-4.

10. Sergentanis TN, Diamantaras AA, Perlepe C, Kanavidis P, Skalkidou A, Petridou ET. IVF and breast cancer: a systematic review and meta-analysis. Hum ReprodUpdate. 2014;20:106-23.

11. Taheripanah R, Balash F, Anbiaee R, Mahmoodi M, Akbari Sene A. Breast cancer and ovulation induction treatments. Clin Breast Cancer. 2018;18:395-9.

12. Zhao J, Li Y, Zhang Q, Wang Y. Does ovarian stimulation for IVF increase gynaecological cancer risk? A systematic review and meta-analysis. Reprod Biomed Online. 2015:31:20-9.

13. Hatzipetros I, Gocze PM, Cziraky K, Kovacs K, Kalman E, Farkas B. Assessment of cells in the ascitic fluid of women with ovarian hyperstimulation syndrome: the clinical implications for subsequent ovarian malignancy. Reprod Biol Endocrinol. 2013;11:91-5.

14. Mathur RS, Jenkins JM, Bansal AS. The possible role of the immune system in the aetiopathogenesis of ovarian hyperstimulation syndrome. Hum Reprod. 1997;12:2629-34

15. Aboulghar MA, Mansour RT, Serour Gl, El Helw BA, Shaarawy M. Elevated levels of interleukin-2, soluble interleukin-2 receptor alpha, interleukin-6, soluble interleukin- 6 receptor and vascular endothelial growth factor in serum and ascitic fluid of patients with severe ovarian hyperstimulation syndrome. Eur J Obstet Gynecol Reprod Biol. 1999;87:81-5.

16. Andus T, Gross V, Holstege A, Weber M, Ott M, Gerok W, Schölmerich J. Evidence for the production of high amounts of interleukin- 6 in the peritoneal cavity of patients with ascites. J Hepatol. 1992;15:378-81.

17. Hoeben A, Landuyt B, Highley MS, Wildiers H, Van Oosterom AT, De Bruijn EA. Vascular endothelial growth factor and angiogenesis. Pharmacol Rev. 2004:56:549-80. 
18. Bates DO. Vascular endothelial growth factors and vascular permeability Cardiovasc Res. 2010;87:262-71.

19. Elchalal U, Schenker JG. The pathophysiology of ovarian hyperstimulation syndrome--views and ideas. Hum Reprod. 1997:12:1129-37.

20. Namavar Jahromi B, Parsanezhad ME, Shomali Z, Bakhshai P, Alborzi M, Moin Vaziri N, Anvar Z. Ovarian hyperstimulation syndrome: a narrative review of its pathophysiology, risk factors, prevention, classification, and management. Iran J Med Sci. 2018:43:248-60.

21. Krasnow JJ, Berga SL, Guzick DS, et al. Vascular permeability factor and vascular endothelial growth factor in ovarian hyperstimulation syndrome. Fertil Steril. 1996;65:552-5.

22. Abramov Y, Barak V, Nisman B, Schenker JG. Vascular endothelial growth factor plasma levels correlate to the clinical picture in severe ovarian hyperstimulation syndrome. Fertil Steril. 1997;67:261-5.

23. Dalal V, Kumar R, Kumar S, Sharma A, Kumar L, Sharma JB, Roy KK, Singh N, Vanamail P. Biomarker potential of IL-6 and VEGF-A in ascitic fluid of epithelial ovarian cancer patients. Clin Chim Acta. 2018;482:27-32.

24. Chen CD, Wu MY, Chen HF, Chen SU, Ho HN, Yang YS. Prognostic importance of serial cytokine changes in ascites and pleural effusion in women with severe ovarian hyperstimulation syndrome. Fertil Steril. 1999; 72:286-92.

25. Köhidai L, Csaba G. Chemotaxis and chemotactic selection induced with cytokines (IL-8, RANTES and TNF-alpha) in the unicellular Tetrahymena pyriformis. Cytokine. 1998;10:481-6.

26. Revel A, Barak V, Lavy Y, Anteby E, Abramov Y, Schenker JJ, Amit A, FinciYeheskel Z, Mayer M, Simon A, Laufer N, Hurwitz A. Characterization of intraperitoneal cytokines and nitrites in women with severe ovarian hyperstimulation syndrome. Fertil Steril. 1996;66:66-71.

27. Manolopoulos K, Lang U, Gips H, Braems GA. Elevated interleukin-10 and sex steroid levels in peritoneal fluid of patients with ovarian hyperstimulation syndrome. Eur J Obstet Gynecol Reprod Biol. 2001;99:226-31.

28. Brat DJ, Bellail AC, Van Meir EG. The role of interleukin-8 and its receptors in gliomagenesis and tumoral angiogenesis. Neuro-Oncology. 2005;7:122-33.

29. Brencicova E, Jagger AL, Evans HG, Georgouli M, Laios A, Attard Montalto S, Mehra G, Spencer J, Ahmed AA, Raju-Kankipati S, Taams LS, Diebold SS. Interleukin-10 and prostaglandin E2 have complementary but distinct suppressive effects on toll-like receptor-mediated dendritic cell activation in ovarian carcinoma. PLoS One. 2017;12:e0175712.

30. Friedlander MA. Loret de Mola JR, Goldfarb JM: elevated levels of interleukin-6 in ascites and serum from women with ovarian hyperstimulation syndrome. Fertil Steril. 1993;60:826-33.

31. Massagué J. TGF $\beta$ signalling in context. Nat Rev Mol Cell Biol. 2012;13:616-30.

32. Santin AD, Bellone S, Ravaggi A, Roman J, Smith CV, Pecorelli S, Cannon MJ, Parham GP. Increased levels of interleukin-10 and transforming growth factor-beta in the plasma and ascitic fluid of patients with advanced ovarian cancer. BJOG. 2001;108:804-8.

33. Lisa C. Grossman, Konstantinos G. Michalakis, hyacinth Browne, mark D. Payson, James H. Segars: the pathophysiology of ovarian hyperstimulation syndrome: an unrecognized compartment syndrome. Fertil Steril. Author manuscript; available in PMC 2011 Jun 27. Fertil Steril. 2010;94:1392-8.

34. Bódis J, Papp S, Vermes I, Sulyok E, Tamás P, Farkas B, Zámbó K, Hatzipetros I, Kovács GL. "Platelet-associated regulatory system (PARS)" with particular reference to female reproduction. J Ovarian Res. 2014;16(7):55-60.

\section{Publisher's Note}

Springer Nature remains neutral with regard to jurisdictional claims in published maps and institutional affiliations.

Ready to submit your research? Choose BMC and benefit from:
- fast, convenient online submission
- thorough peer review by experienced researchers in your field
- rapid publication on acceptance
- support for research data, including large and complex data types
- gold Open Access which fosters wider collaboration and increased citations
- maximum visibility for your research: over 100M website views per year
At BMC, research is always in progress.
Learn more biomedcentral.com/submissions

